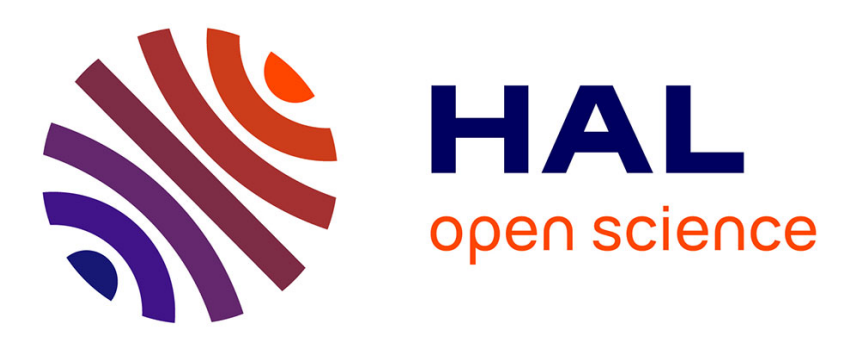

\title{
Experimental and theoretical investigation of highly nonlinear optical glasses
}

Lionel Canioni, Laurent Sarger, P. Segonds, A. Ducasse, Claire Duchesne, Evelyne Fargin, Roger Olazcuaga, Gilles Le Flem

\section{To cite this version:}

Lionel Canioni, Laurent Sarger, P. Segonds, A. Ducasse, Claire Duchesne, et al.. Experimental and theoretical investigation of highly nonlinear optical glasses. Journal de Physique IV Proceedings, 1994, 04 (C4), pp.C4-285-C4-288. 10.1051/jp4:1994470 . jpa-00252733

\section{HAL Id: jpa-00252733 https://hal.science/jpa-00252733}

Submitted on 1 Jan 1994

HAL is a multi-disciplinary open access archive for the deposit and dissemination of scientific research documents, whether they are published or not. The documents may come from teaching and research institutions in France or abroad, or from public or private research centers.
L'archive ouverte pluridisciplinaire HAL, est destinée au dépôt et à la diffusion de documents scientifiques de niveau recherche, publiés ou non, émanant des établissements d'enseignement et de recherche français ou étrangers, des laboratoires publics ou privés. 


\title{
Experimental and theoretical investigation of highly nonlinear optical glasses
}

\author{
L. CANIONI, L. SARGER, P. SEGONDS, A. DUCASSE, C. DUCHESNE* , E. FARGIN*, \\ R. OLAZCUAGA* and G. LE FLEM*
}

Centre de Physique Moléculaire Optique et Hertzienne, CNRS, Université de Bordeaux I, 351 Cours de la Libération, 33405 Talence, France

* Laboratoire de Chimie du Solide, CNRS, Université de Bordeaux I, 351 Cours de la Libération, 33405 Talence, France

\section{ABSTRACT}

Glasses containing hyperpolarizable entities have a potential and scientifical interest for their nonlinear optical properties. Within this scope glasses of the $\mathrm{Na}_{2} \mathrm{O}-\mathrm{TiO}_{2}-\mathrm{P}_{2} \mathrm{O}_{5}$ system have been investigated with a high sensitivity absolute interferometric technique.

The values of the third order nonlinear susceptibilities will be discussed from the structural point of view and by extension to glasses of the bond orbital theory of Lines [3].

\section{INTRODUCTION}

Transparent glasses with relatively large non linearities are promising materials for fiber optics and all optical switching applications [1]. The choice of composition is mainly dictated by the possibility of increasing the non linear coefficient $\mathrm{n}_{2}$, but various other parameters must be considered, such as high damage threshold, ultrafast response time and easiness of wave guide fabrication process. A pertinent figure of merit $F$ is useful for the selection of materials $\left(\mathrm{F}=\Delta \mathrm{n}_{\mathrm{fas}} / \Delta \mathrm{n}_{\text {slow }}\right)$ where $\Delta \mathrm{n}_{\mathrm{fast}}$ corresponds to the fast contribution to the non linearity, the non linear Ker effect for instance and $\Delta \mathbf{n}_{\text {slow }}$ is related to the slow contributions whose accumulated effect decreases the efficiency of the glass. The thermal non linearity due to the absorption of the laser wave is a classical example of such a spurious effect.

From a recent analysis of the non linear refractive index in crystals by Adair et al. [2], the highest values of $\mathrm{n}_{2}$ are found for titanium oxides. Moreover, M.E. Lines [3], recently discussed the influence of $d$ orbitals on $\mathrm{n}_{2}$ value in transition metal oxides and concluded about the determinant effect of $\mathrm{Ti}^{4+}$. Within this scope, the present paper summarizes the non linear properties of glasses of the $\mathrm{Na}_{2} \mathrm{O}-\mathrm{TiO}_{2}-\mathrm{P}_{2} \mathrm{O}_{5}$ system where $\mathrm{P}_{2} \mathrm{O}_{5}$ was selected as glass forming oxide and sodium ions introduced to make the ion exchange process easier.

\section{EXPERIMENTAL}

Samples were prepared as previously described [4]. Table I gives the compositions, the glass transition temperatures and the densities of the investigated materials. Their high optical quality was checked by strioscopy and by the low value of the absorption coefficient in the near infra-red region. X-ray absorption spectroscopy (E.X.A.F.S. and X.A.N.E.S.) was used to elucidate the structural environment of titanium as a function of composition [5].

\begin{tabular}{|c|c|c|c|c|}
\hline \multicolumn{3}{|c|}{ Molar comoosition } & $\angle \mathrm{TQ}\left( \pm 5^{\circ} \mathrm{C}\right)$ & $\rho\left(=0.02 \mathrm{~g}^{\prime} \mathrm{cm}^{3}\right)^{0}$ \\
\hline Non & $\mathrm{nin}_{2}$ & $890 \%$ & 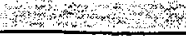 & $3 \times,+3$ \\
\hline 59.2 & 8.1 & 32.7 & $3+3$ & 2.52 \\
\hline 53.0 & 13.5 & 33.5 & 400 & 2.67 \\
\hline .47 .5 & 19.0 & 33.5 & 431 & 2.72 \\
\hline 44.16 & 23.06 & 32.78 & 468 & 2.75 \\
\hline 45.33 & 23.93 & 30.74 & 473 & 2.76 \\
\hline 40.22 & 32.64 & 27.14 & 536 & 2.85 \\
\hline
\end{tabular}

Table I: Compositions, temperature transitions, densities of glasses $\mathrm{Na}_{2} \mathrm{O}-\mathrm{TiO}_{2}-\mathrm{P}_{2} \mathrm{O}_{5}$ 
In order to measure all the relevant contributions to the third order susceptibilities, we set up an improved sampling interferometry technique and obtained the fast response contribution as well as the thermal non-linear behaviour due to the ultralow absorption coefficient.

The experimental setup is schematically represented in fig 1 . A C.W mode locked Titaniumsapphire laser (MIRA 900 , COHERENT), producing $100 \mathrm{fs}$ pulses, $100 \mathrm{~kW}$ peak power at 80 $\mathrm{MHz}$ repetition rate is used. The laser beam is split into two unequal parts. The weaker part is sent into a Mach-Zhender interferometer whose two outputs are used to lock, via a piezoelectric transducer $P 1$, the phase difference between the reference and the probe beam. The phase precision is of the order of one milliradian. The pump beam, modulated by an electrooptic effect at $\mathrm{F}=10 \mathrm{kHz}$, propagates colinearly with the probe beam through the sample. The optical delay D-I provides the required time resolved measurement. In this particular configuration, in order to avoid a coupling problem, a polarisation selection scheme with Glan prisms was used. Fourier analysis of the interferometer output versus the time delay D-I gives the nonlinear phase shift induced by the pump beam of peak power PC . A typical scan is inserted in fig 1 .
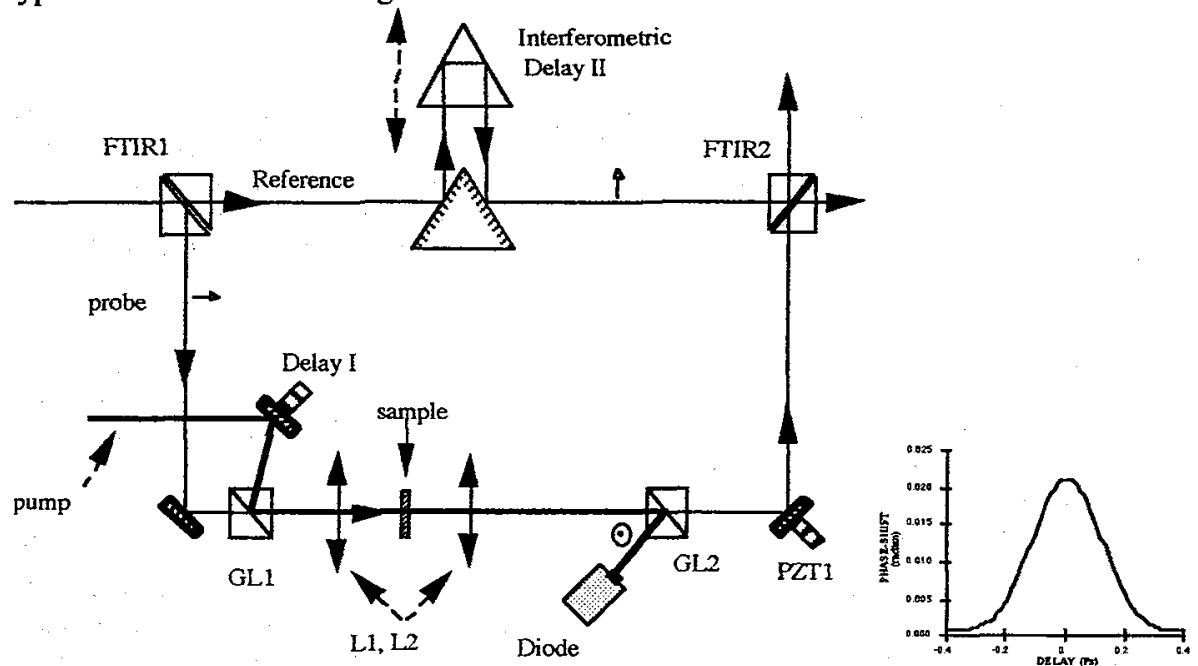

Fig 1: Experimental setup and typical result for a TiO glass (25\%)

As all the relevant parameters -power, beam profile wo in the sample of length 1 , pump $\tau_{\mathbf{p}}$ and probe $\tau_{S}$ pulse width, wavelength $\lambda$, time delay $\tau$ and interferometer sensitivity - are precisely measured, absolute value of the non linearity $\mathbf{n} 2$ can then be easily computed when the response is essentially electronic. For such glasses, the response width is similar to the crosscorelation between pump and probe beam and we obtain at zero delay D-I:

$$
\mathbf{n}_{2}^{e}=\frac{\left(\delta \phi_{\max }(\tau=0)\right) \lambda^{2} \sqrt{1+\tau_{p}^{2} / \tau_{s}^{2}}}{\mathbf{p}_{\mathbf{p}}^{\mathrm{c}} 4 \pi \arctan \left(\frac{1 \lambda}{2 \pi \mathbf{w}_{0}^{2}}\right)}
$$

Absolute values of $\mathbf{n} 2$ have been obtained with modulation of the delay D-I in order to average out all the spurious coherents effects arising in this kind of experiment. The table III gives the non linear index coefficient values $\mathrm{n}_{2}$ of the investigated glasses which increase with $\mathrm{TiO} 2$ concentration. The $\mathrm{n}_{2}$ value of the non linear standard glass SF 59, measured in the same interferometric conditions, $9.7 \cdot 10^{-19} \mathrm{~m}^{2} / \mathrm{W}$, which is consistent with other published data [11], is only $30 \%$ larger than that of the highest titanium concentration (35\%) phosphate glass. The non linear response at negative delay is related to accumulated slow effects mainly due to residual absorption. Although a complete thermal analysis is still needed to infer from these data the absorption coefficient, the evaluation of the figure of merit of the glasses can be made by comparison with that of the SF 59. As the residual non linear response of this standard is 600 times higher than that of the richest titanium investigated glasses, the 
corresponding figure of merit is approximately in the ratio $1 / 250$ between the SF 59 and this phosphate glass.

\section{Structural analysis}

In order to relate the observed high nonlinear indexes to structural data in a fashion similar to the polymer approach, the crucial factor appears to be the determination of the titanium atom environment and its evolution as the concentration of $\mathrm{TiO} 2$ increases in the glasses. This objective was reached by a detailed X-ray absorption spectroscopy investigation. The combined X.A.N.E.S. and E.X.A.F.S. data are consistent with the presence of two different types of titanium sites : $\mathrm{Ti}$ atoms are located in octahedra and square-based pyramids. More precisely the E.X.A.F.S. analysis gives evidence of the existence of short TiO distances (1.61-1.69 $\stackrel{0}{A}$ ) which are typical of the distances usually observed in several crystals of titanates exhibiting TiOS pyramidal groups $[7,8,9,10]$, whereas the other titanium oxygen mean distance is about $1.95 \AA$. Moreover, the proportion of pyramid increases with the titanium concentration.

For the highest titanium concentration glasse additional E.X.A.F.S. signals indicate the presence of titanium atoms in the second coordination shell of a given $\mathrm{Ti}$ at a distance of 3.4 Angstrom. The unusual high intensity of these signals can be produced by an intermediate oxygen in the quasi alignment of the two titanium atoms. Consequently Ti-O-Ti-O-Ti-O--. KTiOPO4 like chains [10] are constructed in the glass matrix. The results of the E.X.A.F.S. investigation are collected in Table II.

\begin{tabular}{|c|c|c|c|}
\hline$\alpha_{\pi} \pi$ & Ho Bond & $\forall \mathrm{N}_{\mathrm{N}}$ & $\mathrm{k}(\mathrm{A})$ \\
\hline \multirow[t]{2}{*}{8.1} & $\pi-0$ & 3 & $1.90 \pm 0.02$ \\
\hline & $T+0$ & 1 & $1.61 \pm 0.03$ \\
\hline \multirow[t]{2}{*}{19.0} & $\pi-0$ & 4 & $1.91 \pm 0.02$ \\
\hline & Tino & 1 & $1.57 \pm 0.03$ \\
\hline \multirow[t]{3}{*}{23.9} & $T_{i j}=0$ & 4 & $4.95 \pm 0.02$ \\
\hline & $\pi \infty$ & I & $1.69 \pm 0.03$ \\
\hline & $T_{t}=T_{I}$ & 1 & 3.38 \\
\hline \multirow[t]{3}{*}{32.6} & THOO & 4 & $1.94 \pm 0.02$ \\
\hline & Tा-O & 1 & L.66 \pm 0.03 \\
\hline & $T \mathrm{~T}-\mathrm{Ti}$ & 1 & 3.40 \\
\hline
\end{tabular}

Table II E.X.A.F.S data for glasses in the $\mathrm{Na}_{2} \mathrm{O}-\mathrm{TiO}_{2}-\mathrm{P}_{2} \mathrm{O}_{5}$ system $R$ : Interatomic distances; $N$ : Number of neighbors

\section{THEORETICAL ASPECT}

The linear and non linear characteristics of these materials have been calculated adapting for glasses the bond orbital theory recently introduced by Lines [3] (describing the linear and non linear electronic response of optically transparent crystals). The representative bonding orbital between cation and anion, here titanium and oxygen, is written as a linear combination of an anionic orbital and two cationic orbitals of $\mathrm{d}$ and sp character respectively. Once variational calculus gives the set of the corresponding three molecular orbitals, then the influence of the electrical field can be developped by classical perturbation treatment. For instance the microscopic third order non linear optical response can be expressed as :

$$
\chi_{\mathrm{b}}{ }^{(3)}=\chi_{\mathrm{sp}}{ }^{(3)}+\chi_{\mathrm{d}}{ }^{(3)}-\mathrm{f} \cdot \chi_{\mathrm{sp}}{ }^{(1)} \cdot \chi_{\mathrm{d}}{ }^{(1)}\left(\mathrm{E}_{\mathrm{s}}{ }^{-1}+\mathrm{E}_{\mathrm{s}}{ }^{1}\right)
$$

where $b$ is the pertubated molecular orbital, $\chi^{(n)}$ the nth-order susceptibility, $E_{S}$ and $E_{S}$ the Sellmeier gaps for $\mathrm{sp}$ and $\mathrm{d}$ orbitals respectively and $\mathrm{f}$ is the local field correction. From several experimental data, Lines deduces empirical laws which allow to calculate $E_{S}$ and $E_{S}^{\prime}$ and then $\chi_{b}{ }^{(3)}$ for a given metal oxygen distance. 
(3)

We first calculate in our samples $\chi_{b}$ for both Ti-O distances $1.94 \pm 0.02 \AA$ (b1) and $1.67 \pm$ $0.02 \AA$ ( $\left.b_{2}\right)$ evidenced by EXAFS (1). We then averaged over all bond directions with regard to the field orientation $(\beta)$. For such isotropic materials all orientations are assumed to be statistically equivalent. Then, the third order macroscopic susceptibility is expressed by:

$$
\chi_{\text {xcu }}^{(3)}=\left(\chi_{b 1}^{(3)} m_{1} x_{1}+\chi_{b 2}^{(3)} m_{2} x_{2}\right) f A Z\left\langle(\cos \beta)^{4}\right\rangle N_{0}
$$

where $A$ is the number of $b$ electrons in the unit volume which have been estimated for each type of bond from XANES results, $\mathrm{Z}$ is the number of electrons per anion, No is the number of titanium atoms per unit volume, $b_{i}, m_{i}$ are respectively the mean Ti-O distance and the number of bonds at the site $i$ in xi proportions. Absolute theoretical values of $n_{2}$ are presented in table III and compared with experimental interferometric values with no fitting parameter. The non linear indexes calculated with and without introduction of the frequency dependence are compared in Table III with the experimental values. Clearly the best agreement is observed for the richest titanium glasses for which the contribution of the sodium phosphate matrix to the non linear response becomes negligible.

\begin{tabular}{|c|c|c|c|}
\hline (10\% & 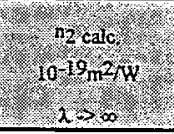 & $\begin{array}{l}\mathrm{n}_{2} \mathrm{cal} \\
10^{-1} \mathrm{~m}^{2} \mathrm{~W} \\
7+800 \mathrm{nnt}\end{array}$ & $\begin{array}{l}n_{2} \mathrm{enp} \\
10^{19} \mathrm{~m}^{2} \mathrm{w} \\
2-800 \mathrm{mu}\end{array}$ \\
\hline 8.1 & 1.6 & 2.0 & $1.1 \pm 0.1$ \\
\hline 19.0 & 2.7 & 3.9 & $2.0 \pm 0.5$ \\
\hline 23.9 & 3.2 & 4.7 & $5.1 \pm 0.6$ \\
\hline 32.6 & 4.0 & 6.3 & $6.1 \pm 0.3$ \\
\hline
\end{tabular}

Table III: Experimental and calculated indexes of glasses in the $\mathrm{Na}_{2} \mathrm{O}-\mathrm{TiO}_{2}-\mathrm{P}_{2} \mathrm{O}_{5}$ System. $n_{2}$ calc $(\lambda \rightarrow \infty)$ frequency dependance neglected. $n_{2}$ calc $(\lambda=800 \mathbf{n m})$ frequency dependence included.

\section{CONCLUSION}

For the first time, a theoretical phenomenological model is succesfully compared with precise measurements of nonlinear indexes. This new approach of a molecular engineering open a way to elaborate inorganic materials for all optical devices.

\section{REFERENCES}

[1] E.M. VOGEL, J. Am. Ceram. Soc., 72 (1989), 719.

[2] R. ADAIR, L.L. CHASE and S.A. PAYNE, Phys. Rev. B, 39 (1989), 3337.

[3] M.E. LINES, Phys. Rev.B, 43, nœ14 (1991), 11978.

[4] S. KRIMI, A. EL JAZOULI, L. RABARDEL, M. COUZI, I. MANSOURI and G. LE FLEM, J. Solid State Chem., 102 (1993), 400.

[5] E. FARGIN, C. DUCHESNE, R. OLAZCUAGA, G. LE FLEM, C. †CARTIER, L. CANIONI, P. SEGONDS, L. SARGER and A. DUCASSE, J. Non Cryst. Solids, accepted for publication.

[6] L. SARGER, P. SEGONDS, L. CANIONI, F. ADAMIETZ, A. DUCASSE, C.

DUCHESNE, E. FARGIN, R. OLAZCUAGA and G. LE FLEM, J. Opt. Soc. Am.B, accepted for publication

[7] Yu.K. EGOROV-TIAMENKO, M.A. SIMONOV and N.V. BELOV, Sov. Phys. Dokl., 23 (1978), 289.

[8] W.G. MUMME and A.D. WADSLEY, Acta Cryst., B.24 (1968), 1327.

[9] R. MASSE, J.C. GRENIER and A. DURIF, Bull. Soc. Fr. Miner. Cristallogr., 90 (1967), 20.

[10] I. TORDJMAN, R. MASSE and J.C. GUITEL, Z. Kristallogr., 139 (1974), 103.

[11] S.R. FRIBERG and P.W. SMITH, IEEE. J. Quantum Electron. QE 23, nœ 12 (1987), 2089. 